\title{
Reduction in Size of Perforated Postsynaptic Densities in Hippocampal Axospinous Synapses and Age-Related Spatial Learning Impairments
}

\author{
Daniel A. Nicholson, ${ }^{1}$ Rie Yoshida, ${ }^{1}$ Robert W. Berry, ${ }^{1}$ Michela Gallagher, ${ }^{2}$ and Yuri Geinisman ${ }^{1}$ \\ ${ }^{1}$ Department of Cell and Molecular Biology, Feinberg School of Medicine and Institute of Neuroscience, Northwestern University, Chicago, Illinois 60611, \\ and 2 Department of Psychological and Brain Sciences, Johns Hopkins University, Baltimore, Maryland 21218
}

\begin{abstract}
A central problem in the neurobiology of normal aging is why learning is preserved in some aged individuals yet impaired in others. To investigate this issue, we examined whether age-related deficits in spatial learning are associated with a reduction in postsynaptic density (PSD) area in hippocampal excitatory synapses (i.e., with a structural modification that is likely to have a deleterious effect on synaptic function). A hippocampus-dependent version of the Morris water maze task was used to separate Long-Evans male rats into young adult, aged learning-unimpaired, and equally aged learning-impaired groups. Axospinous synapses from the CA1 stratum radiatum were analyzed using systematic random sampling and serial section analyses. We report that aged learning-impaired rats exhibit a marked $(\sim 30 \%)$ and significant reduction in PSD area, whereas aged learning-unimpaired rats do not. The observed structural alteration involves a substantial proportion of perforated synapses but is not observed in nonperforated synapses. These findings support the notion that many hippocampal perforated synapses become less efficient in aged learning-impaired rats, which may contribute to cognitive decline during normal aging.
\end{abstract}

Key words: normal aging; learning deficits; perforated synapses; hippocampus; CA1 stratum radiatum; rat

\section{Introduction}

A cardinal feature of normal aging is an impairment of learning and memory. It has long been noted, however, that this agerelated cognitive dysfunction does not affect all old individuals uniformly; some exhibit preserved cognitive capacities even at advanced chronological age (Rapp and Amaral, 1992; Gallagher et al., 2003). The reasons for such marked individual differences in mnemonic functions during aging remain unknown. Many studies examining cellular substrates of age-related cognitive decline have focused on the hippocampal formation because its structural integrity is a prerequisite for the acquisition of some forms of behavior and because this brain region is especially vulnerable to the process of aging (for review, see Geinisman et al., 1995). Although historically neuronal death was considered the principal cause of learning and memory impairments during normal aging (Cursio et al., 1982), it has been demonstrated with unbiased stereological techniques that deficits in hippocampusdependent spatial learning observed in some aged rats are not associated with neuronal loss (Rapp and Gallagher, 1996; Rasmussen et al., 1996).

An alternative hypothesis is that age-related cognitive deficits

Received May 5, 2004; revised June 28, 2004; accepted June 29, 2004

This work was supported by National Institutes of Health Grants R01 AG17139 (Y.G.), P30 AG13854 (Y.G.), and P01 AG09973 (M.G.).

Correspondence should be addressed to Yuri Geinisman, Northwestern University Medical School, Department of Cell and Molecular Biology, 303 East Chicago Avenue, Ward 7-342, Chicago, IL 60611. E-mail: yurig@northwestern.edu. DOI:10.1523/JNEUROSCI.1725-04.2004

Copyright $\odot 2004$ Society for Neuroscience $\quad 0270-6474 / 04 / 247648-06 \$ 15.00 / 0$ might result from a loss of excitatory hippocampal synapses. The CA1 subfield of the hippocampus has been shown to be necessary for several hippocampus-dependent behaviors (Eichenbaum and Cohen, 2001). A major CA1 synapse-containing layer that exhibits learning-related plasticity is the stratum radiatum (Geinisman, 2000), which contains mainly CA3 $\rightarrow$ CA1 synapses (Amaral and Witter, 1995). Our previous study (Geinisman et al., 2004) tested the supposition that age-related learning impairments are associated with a loss of synapses in the CA1 stratum radiatum. The Morris water maze task, which requires an intact and functional hippocampus, was used to assess spatial learning in young and aged rats and to separate the latter into learningimpaired (AI) and learning-unimpaired (AU) groups. The results, obtained with unbiased stereological methods, showed that total numbers of all axospinous synapses and of their perforated and nonperforated subtypes were not decreased in the CA1 stratum radiatum of aged learning-impaired rats.

In the absence of synaptic loss, spatial learning impairments that are typical of a subpopulation of aged rats may be caused by structural alterations in existing synapses. Of special functional significance in this respect may be changes in the dimensions of the postsynaptic density (PSD), a plate(s) of electron-dense material located on the cytoplasmic face of the postsynaptic membrane (Peters et al., 1991). Postsynaptic receptors for neurotransmitters are most highly concentrated in the PSD (Kennedy, 2000), and a change in PSD size is likely to reflect a corresponding alteration in synaptic glutamate receptor content. In the present study, we examined whether age-related deficits in hippocampus-dependent spatial 
learning are associated with a reduction in PSD area in hippocampal synapses.

\section{Materials and Methods}

The materials and most methods used were the same as in our previous study (Geinisman et al., 2004), and only their brief descriptions are presented below.

Animals. Young adult (YA) (6 months old; $n=6)$ and aged (27 months old; $n=12$ ) male Long-Evans rats (Charles River Laboratories, Raleigh, NC) were examined. The rats were housed singly in a climate-controlled vivarium (ambient temperature, $25^{\circ} \mathrm{C}$ ) maintained on a $12 \mathrm{hr}$ light/dark cycle, food and water being available ad libitum. All animal experiments were approved by the Animal Care and Use Committees of the investigators' institutions.

Behavioral testing. The apparatus and protocol for evaluating spatial learning were the same as in previous experiments (Gallagher et al., 1993). Briefly, the rats were trained on a spatial navigation task in the Morris water maze. Three trials with $60 \mathrm{sec}$ intertrial intervals were administered per day for 8 consecutive days. On each training trial, an animal was released into the maze from one of four equally spaced starting positions around the maze perimeter. The starting position varied from trial to trial, whereas the location of the hidden escape platform remained constant. If a rat failed to escape within $90 \mathrm{sec}$, it was guided to the platform where it remained for $30 \mathrm{sec}$. Every sixth trial was a probe trial. During these trials, the platform was retracted to the maze bottom for 30 initial seconds and then raised to its normal position for completion of the trial. Throughout testing, the search paths were monitored by a video tracking system and analyzed with custom-designed software. On the day after completion of the protocol with the hidden platform, the rats were tested for one session of six trials ( $30 \mathrm{sec}$ intertrial intervals) on a nonspatial hippocampus-independent version of the water maze task using a visible platform marked by cues. From trial to trial, the location of the visible platform was varied randomly among the maze quadrants. Each rat was allowed $30 \mathrm{sec}$ to reach the platform.

Electron microscopy. The rats were deeply anesthetized (ketamine hydrochloride, $90 \mathrm{mg} / \mathrm{kg}$; xylazine, $10 \mathrm{mg} / \mathrm{kg}$ ) and transcardially perfused in three consecutive steps: (1) PBS, pH 7.3, injected at a rate of $50 \mathrm{ml} / \mathrm{min}$ for $40 \mathrm{sec}$; (2) $1 \%$ paraformaldehyde, $1.25 \%$ glutaraldehyde, and $0.02 \mathrm{~mm}$ $\mathrm{CaCl}_{2}$ in $0.12 \mathrm{M}$ phosphate buffer, $\mathrm{pH} 7.3$, administered initially at a rate of $50 \mathrm{ml} / \mathrm{min}$ for $10 \mathrm{~min}$ and thereafter at a rate of $25 \mathrm{ml} / \mathrm{min}$ for an additional $20 \mathrm{~min}$; and (3) the same fixative at twice the aldehyde concentration delivered at a rate of $25 \mathrm{ml} / \mathrm{min}$ for $10 \mathrm{~min}$. The right hemisphere was postfixed in the double-strength fixative at $4^{\circ} \mathrm{C}$ overnight. The hippocampal formation was then dissected free and cut, perpendicular to its septotemporal axis, into consecutive 0.8 -mm-thick transverse slabs in a systematic random manner. The slabs were treated with $\mathrm{OsO}_{4}$ and flat embedded in Araldite (Electron Microscopy Sciences, Fort Washington, PA). Six sampling fields were selected in the CA1 stratum radiatum of each animal using the procedure of systematic random sampling (Geinisman et al., 1996). A series of consecutive ultrathin sections was prepared from each sampling field, counterstained with uranyl acetate-lead citrate, and used to obtain electron micrographs. Synapses were sampled with the aid of the physical disector method, as described previously (Geinisman et al., 1996, 2004). The length of PSD profiles was then measured on electron micrographs of serial sections through each sampled synapse, provided that all profiles of a given PSD could be unequivocally traced. The thickness of ultrathin sections was estimated with Small's technique of minimal folds, and the PSD area was then calculated as specified previously (Geinisman et al., 2000). Planar reconstructions of PSD plates were made according to the approach introduced by Peters and Kaiserman-Abramof (1969). The data reported here are derived from measurements of 95-194 (mean, 141) perforated PSDs and 155221 (mean, 196) nonperforated PSDs per animal.

Statistical analyses. The statistical significance of differences among the three groups of rats was evaluated with an ANOVA. When the differences were significant, subsequent comparisons between different pairs of groups were made with the Games-Howell post hoc multiple comparison procedure $(p<0.05)$, specifically its conservative variant (Howell,
1982). Additionally, distributions of the data were compared with $\chi^{2}$ tests.

\section{Results}

\section{Behavioral characterization of animals}

We tested the spatial learning capacity of young adult (6 months old) and aged (27 months old) rats using a hippocampusdependent version of the Morris water maze task. The rats were administered training trials to assess acquisition with a search error measure and probe trials to assess search strategy in locating an invisible escape platform with the learning index computed as the average proximity (in centimeters) of a given rat to the target platform (Gallagher et al., 1993). Therefore, low index values indicate more accurate search patterns acquired more rapidly during learning, whereas high index values signify poor performance. Aged rats were impaired overall relative to young adults in acquisition of the task during subsequent training trials $\left(F_{(1,16)}=8.73 ; p<0.01\right)$. Individual learning index scores from performance on the interpolated probe trials were also significantly different for aged rats relative to young adults $\left(F_{(1,16)}=\right.$ 4.66; $p<0.05)$. Importantly, a subset of aged rats had learning index scores within the range of performance demonstrated by young adults, whereas the remaining aged rats fell outside this range. Thus, the YA, AU, and AI groups examined in this study consisted of rats (six per group) that had learning index scores of $\leq 229$, $\leq 236$, and $\geq 271$, respectively.

We then trained the animals on a nonspatial hippocampusindependent version of the water maze task using a visible escape platform. This task tested visual acuity and swimming ability of the rats independently of their potential to learn novel spatial information. The ability of all aged rats to locate the visible escape platform was not impaired, and the mean escape latencies were not significantly different among the groups of animals under study (data not shown).

\section{Ultrastructure of synapses in the rat CA1 stratum radiatum}

For electron microscopic analyses, the animals were assigned code numbers that were decoded after completion of morphological work. Brain tissue was collected 4 weeks after the termination of the behavioral testing to allow possible effects of spatial learning on synaptic morphology to dissipate. A pilot study using different aged rats showed that their performance on the Morris water maze task remained the same (either preserved or impaired) over a period of 4 weeks. Examination of electron micrographs of serial sections confirmed previous observations (Harris and Kater, 1994) that the synaptic population of the rat CA1 stratum radiatum consists of axodendritic synapses involving dendritic shafts and axospinous synapses involving dendritic spines. Axodendritic asymmetrical synapses that involve spiny dendrites of CA1 pyramidal cells and that are considered to be excitatory in function were encountered rarely, and we analyzed only axospinous synapses. The latter could be divided, on the basis of the configuration of their PSDs, into perforated and nonperforated synaptic junctions (for review, see Geinisman et al., 1993; Jones and Harris, 1995). When viewed in consecutive serial sections passing perpendicular or at an angle to the synaptic cleft, perforated PSDs usually exhibit at least one sectional profile showing a discontinuity(s) or perforation(s) that lacks electrondense material (Fig. 1). The PSDs of perforated synapses can assume a fenestrated, horseshoe, or segmented shape (Fig. 1). The PSDs of nonperforated synapses have a simpler shape, which is approximated by that of a disc seen in consecutive sections as continuous profiles (Fig. 1). 


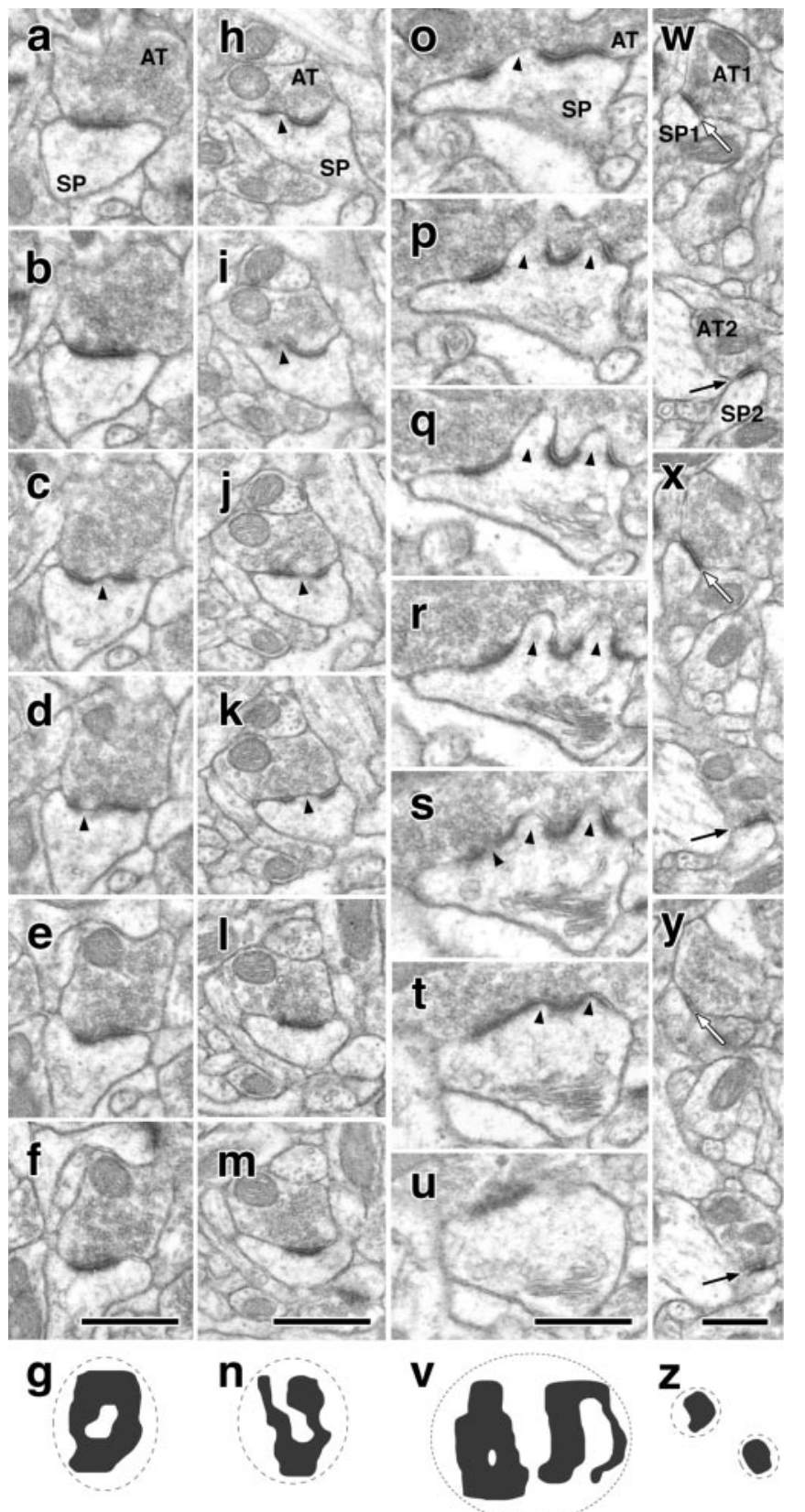

Figure 1. Morphological subtypes of axospinous synapses from the rat CA1 stratum radiatum classified according to their PSD configuration. Electron micrographs of consecutive sections that, respectively, demonstrate a synapse with a fenestrated $(a-f)$, horseshoe-shaped $(h-m)$, or segmented ( $0-u)$ PSD, as well as two synapses (black and white arrows) with nonperforated PSDs $(w-y)$. All micrographs containing PSD profiles are presented in each case. The synapses illustrated in $a-f, h-m$, or $0-u$ belong to the perforated synaptic category because they exhibit a discontinuity(s) or perforation(s) in PSD profiles seen in consecutive sections (arrowheads). In contrast, nonperforated synapses show exclusively continuous PSD profiles in $w-y$. The presynaptic and postsynaptic elements of each synapse are labeled in $a, h, 0$, and $w$ by AT (axon terminal) and SP (spine). Two-dimensional reconstructions of PSD plates show their fenestrated $(g)$, horseshoe-shaped $(n)$, segmented $(v)$, or nonperforated $(z)$ configuration. Scale bars, $0.5 \mu \mathrm{m}$.

\section{Perforated PSD area is diminished in aged learning-impaired rats}

The mean area of perforated PSDs was markedly decreased in the AI group relative to both the YA (by 29.6\%) and AU (by 26.7\%) groups, whereas the latter two groups differed only slightly (by $4.0 \%$ ) from each other (Fig. $2 a$ ). In contrast, the mean area of

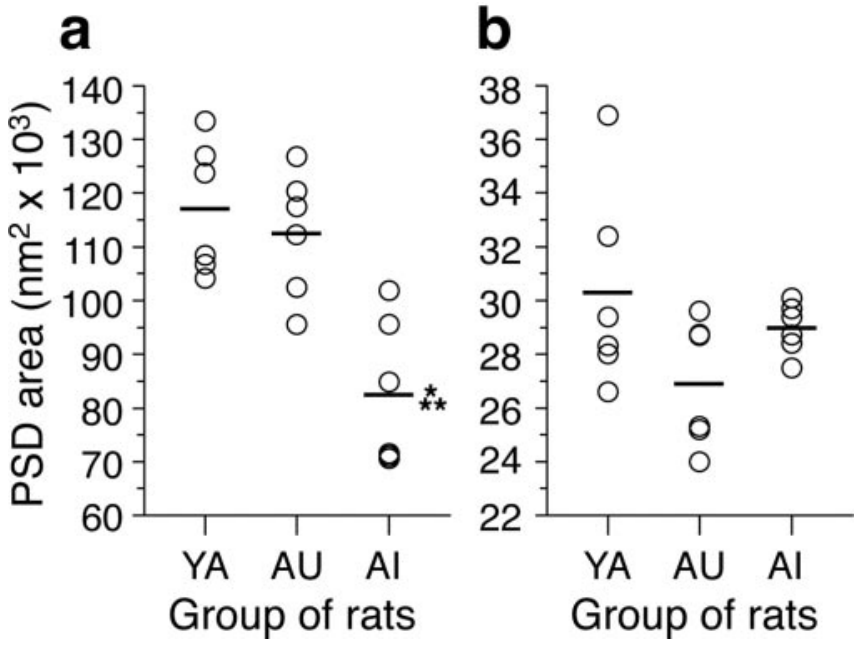

Figure 2. The area of PSDs in axospinous synapses from the CA1 stratum radiatum of $Y A, A U$, and AI rats. Symbols represent the values for individual rats. Horizontal lines indicate the group means. $a$, Perforated PSDs have a significantly smaller area in Al rats relative to either YA $\left(^{*}\right)$ or $\mathrm{AU}\left({ }^{*}\right)$ rats, whereas the latter two groups of animals do not differ significantly on this measure. The means \pm SD for the $Y A, A U$, and Al groups are $117.2 \pm 12.3,112.5 \pm 11.7$, and $82.5 \pm 13.8 \mathrm{~nm}^{2} \times 10^{3}$, respectively. $b$, Nonperforated PSD areas are not significantly different among the three groups of rats. The means $\pm S D$ for the $Y A, A U$, and Al groups are $30.3 \pm$ $3.8,26.9 \pm 2.4$, and $29.0 \pm 1.0 \mathrm{~nm}^{2} \times 10^{3}$, respectively. Note that the scale of the ordinate axis differs from that in $a$.

nonperforated PSDs was similar in the three groups of rats (Fig. $2 b$ ). The statistical significance of the differences was evaluated with a multivariate ANOVA, with group (YA, AU, and $\mathrm{AI}$ ) and PSD configuration (perforated or nonperforated) used as factors. A significant group by PSD configuration interaction $\left(F_{(2,30)}=\right.$ 10.991; $p<0.001)$ was attributable to group differences only among perforated PSDs. Post hoc pairwise group comparisons showed that the mean perforated PSD area was significantly smaller in AI rats than in either AU rats or YA rats and that the difference between the latter two groups was not significant.

To further characterize the change in PSD size, we compared distributions of perforated PSD areas among the groups of rats under study. The $\chi^{2}$ test for several independent samples revealed that the distributions of perforated PSD areas were significantly different among the three groups $\left(\mathrm{df}=36 ; \chi^{2}=307.16 ; p<0.001\right)$. Post hoc pairwise comparisons of the groups on this measure with the $\chi^{2}$ test for two independent samples showed that AU rats did not differ significantly from YA rats $\left(\mathrm{df}=23 ; \chi^{2}=25.51 ; p>0.3\right)($ Fig. $3 a)$. In contrast, the distribution of perforated PSD sizes in AI rats was significantly shifted toward smaller PSD areas relative to YA ( $\mathrm{df}=18$; $\left.\chi^{2}=209.80 ; p<0.001\right)($ Fig. $3 b)$ and $\mathrm{AU}\left(\mathrm{df}=19 ; \chi^{2}=230.56 ; p<\right.$ 0.001 ) (Fig. $3 c$ ) rats. This shift involved many perforated synapses; their proportion within the PSD area range of $10-90 \mathrm{~nm}^{2}$ was substantially larger in the AI group than in the AU (by 31.4\%) and YA (by $29.4 \%$ ) groups.

The observed alterations in perforated PSD area might reflect a selective structural modification of a certain morphological variety(s) of perforated synapses. To determine whether this was the case, we performed separate analyses of perforated synaptic junctions that had a fenestrated, horseshoe-shaped, or segmented PSD (Fig. 4). The data indicated that the mean PSD area in the AI group was reduced in all perforated synaptic subtypes (by 26.9, 29.0 , and $44.2 \%$ relative to the YA group and by $25.9,28.3$, and $27.5 \%$ relative to the AU group for fenestrated, horseshoeshaped, and segmented PSDs, respectively). Additionally, the 

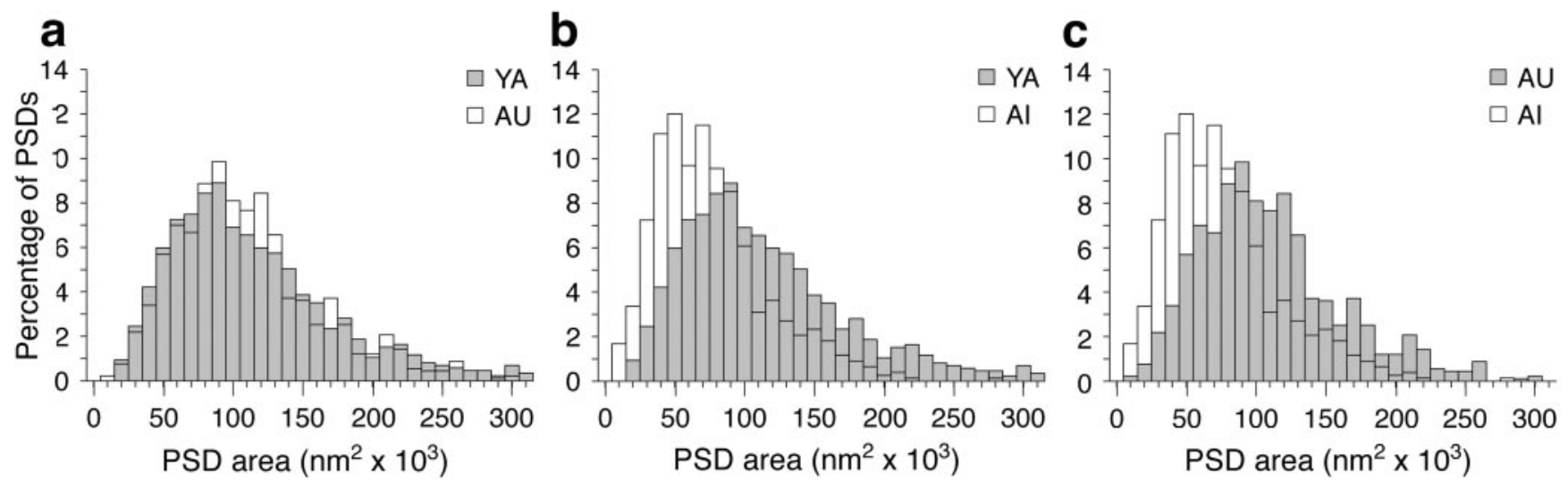

Figure 3. Distribution of perforated PSDs with respect to their area in $\mathrm{YA}, \mathrm{AU}$, and Al rats. $a, \mathrm{YA}$ and $\mathrm{AU}$ rats have almost identical distributions. $b, c$, The distribution in Al rats is skewed toward smaller PSD areas compared with YA $(b)$ and $A U(c)$ rats.

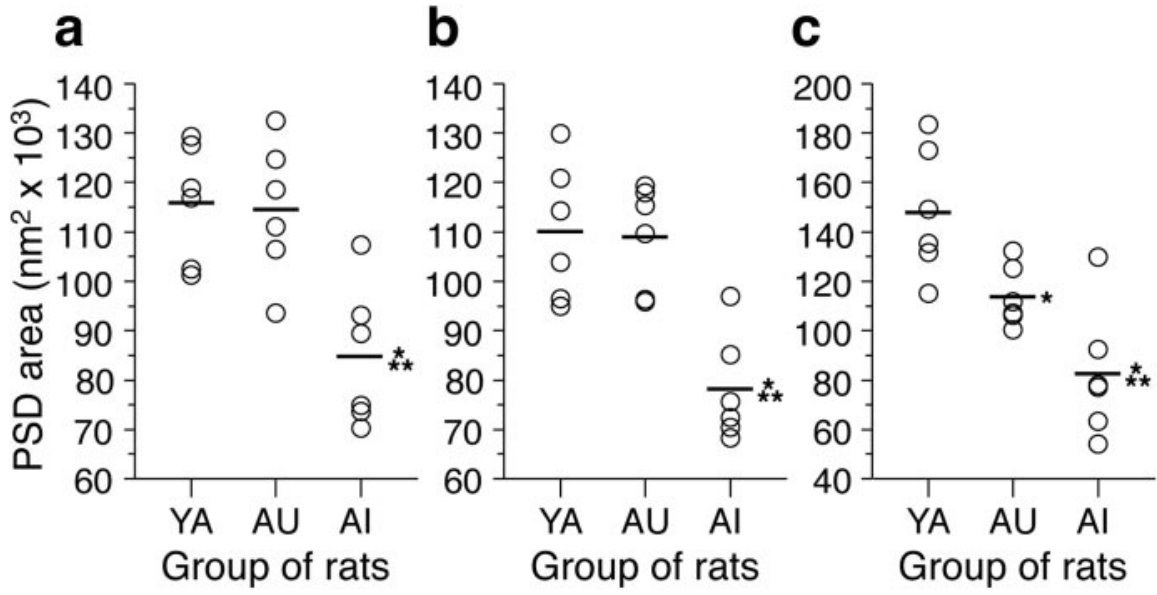

Figure 4. The area of fenestrated, horseshoe-shaped, and segmented PSDs in the YA, AU, and Al groups. Symbols represent the values for individual rats. Horizontal lines indicate the group means. $a$, The fenestrated PSD area is significantly diminished in the Al group relative to the $Y A(*)$ and $A U(* *)$ groups. The means $\pm S D$ for the $Y A, A U$, and Al groups are $116.0 \pm 12.0,114.5 \pm 13.9$, and $84.8 \pm 14.3 \mathrm{~nm}^{2} \times 10^{3}$, respectively. $b$, The horseshoe-shaped PSD area is significantly smaller in the Al group than in the YA ${ }^{*}$ ) and $\mathrm{AU}\left({ }^{* *}\right)$ groups. The means \pm SD for the YA, AU, and Al groups are $110.0 \pm 14.0,109.1 \pm 10.6$, and $78.2 \pm 10.9 \mathrm{~nm}^{2} \times$ $10^{3}$, respectively. C, The segmented PSD area is reduced in size in both aged groups (AU and AI) compared with the YA group $\left({ }^{*}\right.$ ). The Al group, however, also exhibits a significantly smaller area of segmented PSDs relative to the AU group ${ }^{* *}$ ). The means \pm SD for the $\mathrm{YA}, \mathrm{AU}$, and Al groups are $147.9 \pm 26.1,113.8 \pm 12.4$, and $82.5 \pm 26.8 \mathrm{~nm}^{2} \times 10^{3}$, respectively.

area of segmented PSDs was decreased (by 23.1\%) in AU rats compared with YA rats. An ANOVA with group as a betweensubjects factor and perforated subtype as a within-subjects factor yielded a significant group by perforated subtype interaction $\left(F_{(4,30)}=4.356 ; p<0.01\right)$. Post hoc comparisons revealed that fenestrated, horseshoe-shaped, and segmented PSDs were significantly smaller in the AI group compared with both YA and AU rats. In the AU group, however, only segmented PSDs had a significantly smaller area than those in the young adult group.

\section{Discussion}

\section{Reduction of perforated PSD area is a structural synaptic} correlate of age-related cognitive decline

We report that a marked and significant decrease in PSD area occurs in axospinous perforated synapses of AI rats relative to both AU and YA rats (Fig. 2a). This change is highly selective because it does not involve nonperforated synapses (Fig. 2b). Analysis of the distribution of perforated PSDs with regard to their sizes shows that the reduction in PSD area is characteristic of a significant proportion of perforated synapses in the AI group
(Fig. 3b,c). Additionally, each perforated synaptic subtype, regardless of whether it exhibits a fenestrated, horseshoe-shaped, or segmented PSD, has a significantly smaller PSD in AI rats than in AU or YA rats (Fig. 4). These data, taken together, demonstrate that the impairment of hippocampus-dependent spatial learning in a subpopulation of aged rats is associated with a reduction in the area of perforated PSDs in hippocampal synapses. The validity of our findings is strengthened by the use of methodological procedures such as systematic random sampling of synapses and serial section analyses for obtaining unbiased estimates of the area of PSD plates in perforated and nonperforated axospinous junctions.

\section{Why is PSD area selectively reduced in} perforated axospinous synapses?

Axospinous perforated synapses have been implicated in the maintenance of spatial learning ability in a subset of aged animals (Geinisman et al., 1986) and in activity-dependent synaptic plasticity associated with behavioral learning, induction of hippocampal long-term potentiation, and rearing in complex environments (for review, see Jones and Harris, 1995; Geinisman, 2000). It has been postulated that the formation of perforations in the PSD of axospinous synapses is a structural correlate of an enhanced efficacy of synaptic transmission (Jones and Harris, 1995; Geinisman, 2000), which is believed to underlie learning (Martin and Morris, 2002). This notion is supported by observations indicating that the level of glutamate receptor immunoreactivity is higher in axospinous perforated synapses than in nonperforated ones (Baude et al., 1995; Desmond and Weinberg, 1998). Compared with the latter, perforated synapses contain, respectively, 660 and $80 \%$ more immunogold particles for AMPA receptors (AMPARs) and NMDA receptors (NMDARs) in adult rat CA1 stratum radiatum (Ganeshina et al., 2004a). These findings strongly suggest that axospinous perforated synapses from the CA1 stratum radiatum are especially efficacious because they may evoke synaptic responses with an AMPAR component and, to a lesser degree, NMDAR component of an exceptionally large 
magnitude. Moreover, the total number of perforated synapses in the CA1 stratum radiatum is sizable because it is estimated to be $827 \pm 0.076 \times 10^{6}, 821 \pm 0.093 \times 10^{6}$, and $789 \pm 0.065 \times 10^{6}$ in YA, AU, and AI rats, respectively (Geinisman et al., 2004). Hippocampal perforated synapses may, therefore, play a pivotal role in acquisition of hippocampus-dependent behaviors, which may explain why their PSD size is selectively reduced in AI rats.

\section{The process of normal aging contributes to the reduction of segmented PSD area}

Although the area of segmented PSDs in AU rats significantly exceeds that in AI rats, it is nevertheless significantly smaller (by 23.1\%) than in YA animals (Fig. 4). The latter reduction in PSD area has no effect on behavioral performance of AU rats, which may be attributable to a relatively low magnitude of the change involving only the segmented synaptic subtype. The moderate reduction in segmented $\mathrm{PSD}$ area observed in AU rats relative to YA rats would have no functional consequences provided it is compensated by the abundance of AMPARs associated with these PSDs (Ganeshina et al., 2004b). Because the PSD area is diminished in segmented synapses of both aged groups relative to young adults, this structural alteration reflects the effect of the aging process. Therefore, the substantial reduction (by $44.2 \%$ ) in the area of segmented PSDs detected in AI rats compared with YA animals is related not only to a cognitive decline but also to their advanced chronological age.

\section{Functional implications of the reduction of perforated PSD area in aged learning-impaired rats}

Although the PSD consists of many different components (Kennedy, 2000; Scannevin and Huganir, 2000), the removal of AMPARs from the PSD is the mechanism most likely to weaken the efficacy of synaptic transmission and to diminish the PSD area. AMPARs mediate most of the fast excitatory synaptic transmission, and their number is the major determinant of synaptic efficacy (Malenka and Nicoll, 1999). Being highly dynamic components of the PSD, AMPARs move into and out of the postsynaptic membrane on a timescale of minutes (Bredt and Nicoll, 2003). Additionally, there is a strong positive correlation between PSD area and content of postsynaptic AMPARs in all axospinous (Nusser et al., 1998; Racca et al., 2000) and perforated axospinous (Ganeshina et al., 2004b) synapses from the CA1 stratum radiatum of adult rats. These data support the notion that a loss of postsynaptic AMPARs in AI rats may be a major factor responsible for the reduction of perforated PSD area. The latter structural alteration may also partially result from a loss of NMDARs. This would impede the NMDAR-dependent mechanisms of AMPAR recycling, trafficking, and delivery to postsynaptic spines (Ehlers, 2000; Bredt and Nicoll, 2003). It is also possible that the reduction of perforated PSD area in AI rats is a consequence of deficient interactions among PSD proteins, signaling cascades, and/or the actin network (Hering and Sheng, 2001; Ehlers, 2002), which may disrupt the maintenance of large perforated PSDs and reduce their size. Regardless of whether the PSD area reduction is attributable to mechanisms specific to AMPARs, it is nonetheless conceivable that a substantial proportion of perforated synapses in AI rats express only a few AMPARs. This would render such synapses less efficient or postsynaptically silent and hence contribute to the age-related cognitive decline.

Additional studies are necessary to ascertain whether the reduction of perforated PSD area in AI rats reflects a diminished content of AMPARs, NMDARs, and/or other PSD components.
In any event, the data we report here provide direct evidence that a reduction in the area of perforated PSDs represents a structural synaptic alteration specific to the subpopulation of aged animals with deficits in mnemonic function.

\section{References}

Amaral DG, Witter MP (1995) Hippocampal formation. In: The rat nervous system, Ed 2 (Paxinos G, ed), pp 443-493. New York: Academic.

Baude A, Nusser Z, Molnár E, Mcllhinney RA, Somogyi P (1995) Highresolution immunogold localization of AMPA type glutamate receptor subunits at synaptic and non-synaptic sites in rat hippocampus. Neuroscience 69:1031-1055.

Bredt DS, Nicoll RA (2003) AMPA receptor trafficking at excitatory synapses. Neuron 40:361-379.

Cursio CA, Buell SJ, Coleman PD (1982) Morphology of the aging nervous system: not all downhill. In: Advances in neurogerontology, Vol III (Mortimer JA, Pirozzolo FG, Maletta GJ, eds), pp 7-35. New York: Praeger.

Desmond NL, Weinberg RJ (1998) Enhanced expression of AMPA receptor protein at perforated axospinous synapses. NeuroReport 9:857-860.

Ehlers MD (2000) Reinsertion and degradation of AMPA receptors determined by activity-dependent endocytic sorting. Neuron 28:511-525.

Ehlers MD (2002) Molecular morphogens for dendritic spines. Trends Neurosci 25:64-67.

Eichenbaum H, Cohen NJ (2001) From conditioning to conscious recollection: memory systems of the brain. New York: Oxford UP.

Gallagher M, Burwell R, Burchinal M (1993) Severity of spatial learning impairment in aging: development of a learning index for performance in the Morris water maze. Behav Neurosci 107:618-626.

Gallagher M, Bizon JL, Hoyt EC, Helm KA, Lund PK (2003) Effects of aging on the hippocampal formation in a naturally occurring animal model of mild cognitive impairment. Exp Gerontol 38:71-77.

Ganeshina O, Berry RW, Petralia RS, Nicholson DA, Geinisman Y (2004a) Differences in the expression of AMPA and NMDA receptors between axospinous perforated and nonperforated synapses are related to the configuration and size of postsynaptic densities. J Comp Neurol 468:86-95.

Ganeshina O, Berry RW, Petralia RS, Nicholson DA, Geinisman Y (2004b) Synapses with a segmented, completely partitioned postsynaptic density express more AMPA receptors than other axospinous junctions. Neuroscience 125:615-623.

Geinisman Y (1993) Perforated axospinous synapses with multiple, completely partitioned transmission zones: probable structural intermediates in synaptic plasticity. Hippocampus 3:417-434.

Geinisman Y (2000) Structural synaptic modifications associated with hippocampal LTP and behavioral learning. Cereb Cortex 10:952-962.

Geinisman Y, DeToledo-Morrell L, Morrell F (1986) Aged rats need a preserved complement of perforated axospinous synapses per hippocampal neuron to maintain good spatial memory. Brain Res 398:266-275.

Geinisman Y, DeToledo-Morrell L, Morrell F, Heller RE, Rossi M, Parshall RF (1993) Structural synaptic correlate of long-term potentiation: formation of axospinous synapses with multiple, completely partitioned transmission zones. Hippocampus 3:435-446.

Geinisman Y, DeToledo-Morrell L, Morrell F, Heller RE (1995) Hippocampal markers of age-related memory dysfunction: behavioral, electrophysiological and morphological perspectives. Prog Neurobiol 45:223-252.

Geinisman Y, Gundersen HJG, Van der Zee E, West MJ (1996) Unbiased stereological estimation of the total number of synapses in a brain region. J Neurocytol 25:805-819.

Geinisman Y, Disterhoft JF, Gundersen HJ, McEchron M, Persina IS, Power JM, Van der Zee E, West MJ (2000) Remodeling of hippocampal synapses after hippocampus-dependent associative learning. J Comp Neurol 417:49-59.

Geinisman Y, Ganeshina O, Yoshida R, Berry RW, Disterhoft JF, Gallagher M (2004) Aging, spatial learning, and total synapse number in the rat CA1 stratum radiatum. Neurobiol Aging 25:407-418.

Harris KM, Kater SB (1994) Dendritic spines: structural specializations imparting both stability and flexibility to synaptic function. Annu Rev Neurosci 17:341-371.

Hering H, Sheng M (2001) Dendritic spines: structure, dynamics and regulation. Nat Rev Neurosci 2:880-888.

Howell DC (1982) Statistical methods for psychology, Ed 4. Boston: Duxbury. 
Jones DG, Harris RJ (1995) An analysis of contemporary morphological concepts of synaptic remodeling in the CNS: perforated synapses revisited. Rev Neurosci 6:177-219.

Kennedy MB (2000) Signal-processing machines at the postsynaptic density. Science 290:750-754.

Malenka RC, Nicoll RA (1999) Long-term potentiation-a decade of progress? Science 285:1870-1874.

Martin SJ, Morris RG (2002) New life in an old idea: the synaptic plasticity and memory hypothesis revisited. Hippocampus 12:609-636.

Nusser Z, Lujan R, Laube G, Roberts JD, Molnar E, Somogyi P (1998) Cell type and pathway dependence of synaptic AMPA receptor number and variability in the hippocampus. Neuron 21:545-559.

Peters A, Kaiserman-Abramof IR (1969) The small pyramidal neuron of the rat cerebral cortex. The synapses upon dendritic spines. Z Zellforsch Mikrosk Anat 100:487-506.
Peters AA, Palay SL, Webster HD (1991) The fine structure of the nervous system: neurons and their supporting cell, Ed 3. New York: Oxford UP.

Racca C, Stephenson FA, Streit P, Roberts JD, Somogyi P (2000) NMDA receptor content of synapses in stratum radiatum of the hippocampal CA1 area. J Neurosci 20:2512-2522.

Rapp PR, Amaral DG (1992) Individual differences in the cognitive and neurobiological consequences of normal aging. Trends Neurosci 15:340-345.

Rapp PR, Gallagher M (1996) Preserved neuron number in the hippocampus of aged rats with spatial learning deficits. Proc Natl Acad Sci USA 93:9926-9930.

Rasmussen T, Schliemann T, Sorensen JC, Zimmer J, West MJ (1996) Memory impaired aged rats: no loss of principal hippocampal and subicular neurons. Neurobiol Aging 17:143-147.

Scannevin RH, Huganir RL (2000) Postsynaptic organization and regulation of excitatory synapses. Nat Rev Neurosci 1:133-141. 